\title{
Variability in at-sea foraging behaviour of little penguins Eudyptula minor in response to fine-scale environmental features
}

\author{
Lachlan R. Phillips ${ }^{1, *}$, Mark Hindell ${ }^{1}$, Alistair J. Hobday ${ }^{2}$, Mary-Anne Lea ${ }^{1}$ \\ ${ }^{1}$ Ecology and Biodiversity Centre, Institute for Marine and Antarctic Studies, University of Tasmania, Hobart, \\ Tasmania 7004, Australia \\ ${ }^{2}$ CSIRO Oceans and Atmosphere, Hobart, Tasmania 7000, Australia
}

\begin{abstract}
A long-standing question in ecology is how predators interact with their environment when locating patchily distributed prey. There is some evidence to suggest that marine predators use environmental features as foraging cues at meso-scales $(100-1000 \mathrm{~km})$; however, the role of environmental structure at finer scales $(1-100 \mathrm{~km})$ is less well understood. To investigate how marine predators respond to fine-scale environmental variability, the movement patterns of 29 GPS-tagged little penguins Eudyptula minor from 3 colonies in the highly variable Storm Bay ecosystem in south-eastern Tasmania, Australia, were analysed using hidden Markov behavioural state modelling alongside high-resolution environmental data. Variability in at-sea behavioural states was observed between colonies correlating with differences in fine-scale environmental parameters. There were significant differences in trip metrics and time spent in each of the identified behavioural states between each of the study colonies. Additionally, transitions between behavioural states were associated with different environmental parameters at each site. This variability in foraging behaviour for conspecifics at similar temporal scales illustrates the significance of fine-scale environmental variability in determining at-sea predator behaviour and highlights how even subtle differences in fine-scale environmental parameters can lead to alternative foraging strategies. This flexibility suggests a capacity to behaviourally adapt to variable and changing environmental conditions, a necessary condition for persistence in a changing world.
\end{abstract}

KEY WORDS: Behavioural plasticity $\cdot$ Environmental variability $\cdot$ Ecological patterns $\cdot$ Ecological processes $\cdot$ Ecological modelling $\cdot$ Ecology

\section{INTRODUCTION}

Knowledge of how marine predators interact with their environment when searching for scarce and patchy food resources is fundamental to understanding their biological requirements (Freitas et al. 2008). Marine environments can be difficult to study, as they are spatially and temporally complex with characteristically heterogeneous features that define the landscape (Pollard et al. 2002). As a consequence, the predictability of patchily distributed prey in these environments is often scale-dependent (Weimerskirch 2007). While there has been some research into how

\footnotetext{
${ }^{*}$ Corresponding author: lachlan.phillips.00@gmail.com
}

marine predators use environmental parameters such as sea surface temperature (SST) and salinity as cues for finding prey at meso-scales (100-1000 km) (Trathan et al. 2008, Kappes et al. 2010), how these cues are utilised (directly and/or as a proxy) at fine-scale resolutions (1-100 km) requires further investigation (Trathan et al. 2008, van Eeden et al. 2016) using contemporaneous observations (Mannocci et al. 2017). This is in part due to the ephemeral nature of environmental features at these scales, which reduces the predictability of prey distributions (Weimerskirch et al. 2005). In response to this heterogeneous and variable landscape, marine predators are known to utilise

() The authors 2019. Open Access under Creative Commons by Attribution Licence. Use, distribution and reproduction are unrestricted. Authors and original publication must be credited. 
a range of complex, scale-dependent search patterns and foraging strategies when locating prey (Papastamatiou et al. 2012, Benoit-Bird et al. 2013). Furthermore, these strategies can be highly variable and sitespecific as a consequence of fine-scale differences in local environmental conditions (Angel et al. 2016).

In highly variable marine environments, individuals that are able to adjust foraging strategies to account for changing conditions may demonstrate improved foraging and/or breeding success (Afán et al. 2015). This is particularly important for centralplace foragers such as seabirds, where foraging trip duration during the breeding season is restricted by the fasting ability of their partner or offspring (Angel et al. 2016). There are strong associations between short-range foraging and fine-scale environmental phenomena that may aggregate prey and facilitate prey capture (Ballard et al. 2010, Mattern et al. 2013, Kowalczyk et al. 2015). For example, African penguins Spheniscus demersus are more likely to avoid warm-water intrusions in favour of cool-water upwellings when locating prey (van Eeden et al. 2016); Grecian et al. (2018) found that northern gannets Morus bassanus learn how to target frontal zones, with adults being more proficient than immatures.

Quantifying how seabird species respond to environmental variability allows for an understanding of a population's ecological resilience, defined as the capacity to respond to a perturbation or disturbance (Holling 1973). Seabird responses to environmental variability can be quantified using a variety of approaches, including stable isotope analysis to assess a species' foraging niche (Yamamoto et al. 2016), monitoring of chick growth rates and breeding success (Weimerskirch et al. 2001) and assessing movement patterns through the deployment of GPS logging devices to analyse foraging behaviour (Carroll et al. 2016).

Monitoring animal movement patterns has historically been a difficult task; however, advances in telemetry technologies and associated statistical analyses now allow monitoring animal movement patterns and associated behaviours at very fine spatial and temporal scales (Gurarie et al. 2016, Michelot et al. 2016a, Patterson et al. 2017). To link movement patterns with environmental variability, a novel emerging approach is the decomposition of continuous movement pathways into distinct behavioural types (Langrock et al. 2012, Gurarie et al. 2016, Michelot et al. 2016a), which assumes that most animal movement is driven by switches in underlying behavioural states. To this purpose, hidden Markov models (HMMs) provide particular insight, because of model flexibility and clear interpretability (Langrock et al. 2012).
In the present study, we used HMMs with environmental covariate data from a high-resolution hydrodynamic model to investigate the fine-scale at-sea foraging behaviour of a flightless marine predator, the little penguin Eudyptula minor, in a highly variable marine environment. Like most seabirds, little penguins can cover large areas when foraging (Weavers 1992) and are capable of exploiting smallto large-scale prey patches (Carroll et al. 2017). However, during the breeding season, little penguins become central-place foragers and typically make shorter foraging trips, with at-sea behaviour assumed to be largely dependent on localised variability in environmental parameters (Kowalczyk et al. 2015). While previous studies have found flexibility in little penguin behaviour in response to environmental variability at both population and individual levels (Berlincourt \& Arnould 2015, Kowalczyk et al. 2015, Saraux et al. 2016), few have had the opportunity to investigate if these responses persist at finer scales (1-100 km). We used a cross-sectional study at 3 colonies in Storm Bay, Tasmania, Australia, to investigate little penguin foraging behaviour under differing environmental conditions using high-resolution (1-2 km and hourly) environmental data. Considering the localised, fine-scale environmental variability of Storm Bay and the short range of little penguin foraging trips during the breeding season, we hypothesised that little penguins would demonstrate location-specific responses to fine-scale environmental variability within their foraging ranges, as they adapt to specific environmental circumstances.

\section{MATERIALS AND METHODS}

A total of 3 little penguin colonies (Boronia Beach, Bruny Island and Wedge Island) located around Storm Bay in south-eastern Tasmania were selected for the study (Fig. 1). Storm Bay is a highly dynamic marine ecosystem, exhibiting complex patterns of spatial and temporal variability at fine-scale resolution (Harris et al. 1991, 1992). This variability is driven by the proximity of the bay to the subtropical convergence and the complex interactions of various parental water masses that episodically alter the character of the bay (Cresswell 2000). Storm Bay is primarily influenced by (1) penetration of warm, high-salinity, low-nutrient waters from East Australian Current (EAC) eddies in the summer; (2) advection of cooler, nutrient-rich subantarctic waters in the winter; (3) the winter input of warm, relatively saline waters from the west coast Zeehan (Leeuwin) 


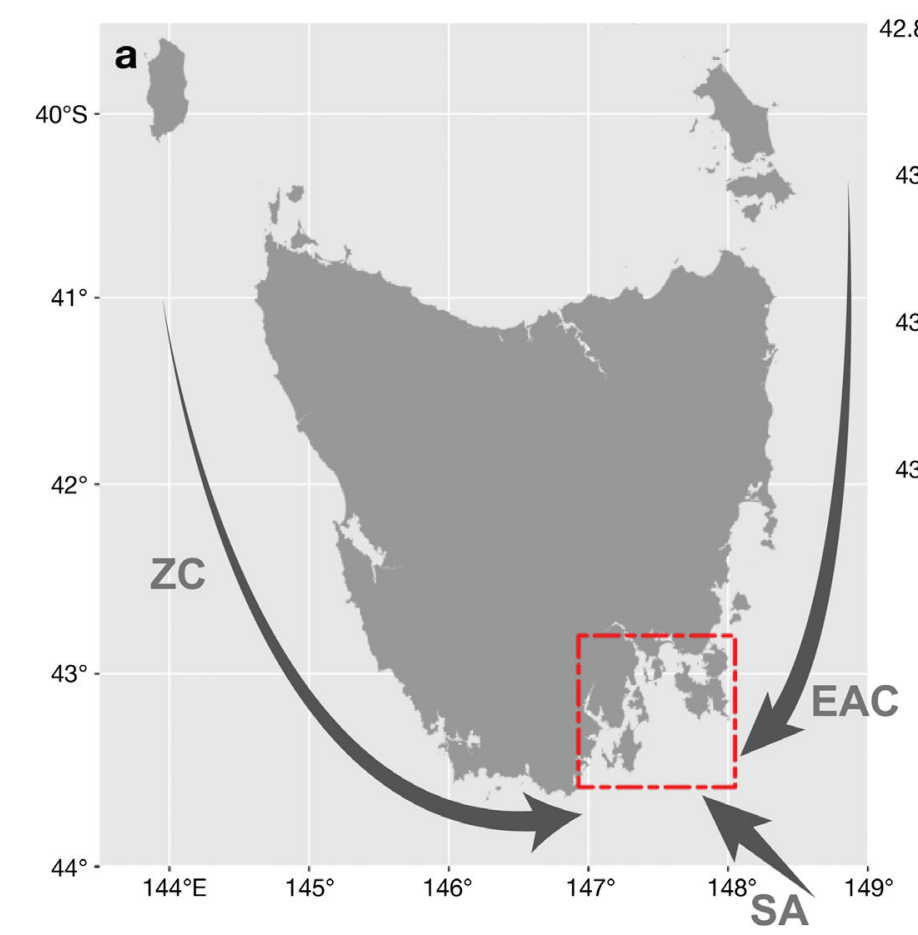

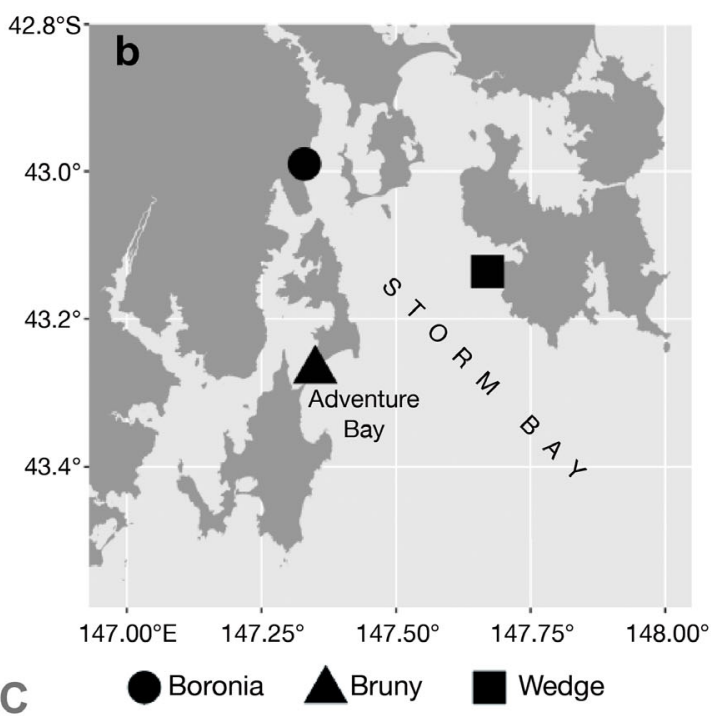

Fig. 1. (a) Storm Bay study region (red rectangle), Tasmania, Australia. Arrows: regional influence of the 3 dominant water masses - the Zeehan Current $(\mathrm{ZC})$; the East Australian Current (EAC); and SubAntarctic water (SA). (b) Study region showing the 3 little penguin colonies investigated in this study
Current; and (4) freshwater input from the Derwent and Huon Estuaries (Ishak 2014). Notably, this region is undergoing rapid ecological change due to the extension of the EAC eddy train, which is warming the east coast of Tasmania at 4 times the global average (Ridgway 2007, Frusher et al. 2014).

The Boronia Beach colony $\left(42.99^{\circ} \mathrm{S}, 147.33^{\circ} \mathrm{E}\right)$ consists of approximately 100 breeding pairs of little penguins and is in close proximity to the urban regions of Kingston Beach and Blackman's Bay. The Bruny Island colony $\left(43.27^{\circ} \mathrm{S}, 147.35^{\circ} \mathrm{E}\right)$ consists of approximately 600 breeding pairs (Vertigan \& Woehler 2014), located along the thin mid-island isthmus. Wedge Island $\left(43.14^{\circ} \mathrm{S}, 147.67^{\circ} \mathrm{E}\right)$ is located $1.25 \mathrm{~km}$ to the west of the Tasman Peninsula and is home to a large colony of approximately 1000 breeding pairs (Vertigan 2010).

Fieldwork was conducted during the peak of the 2015-2016 little penguin breeding season, from 4 December 2015 to 24 January 2016, during the chick rearing phase. Penguins were captured in their burrows and were equipped with a GPS logger (CatTrack; $3.7 \times 2.2 \times 0.8 \mathrm{~mm}, 27 \mathrm{~g}$ ) sealed in electrical heat-shrink for waterproofing. Logging devices were attached to the penguins' lower backs with waterproof cloth tape (Tesa) to minimise drag without impeding the oil gland or restricting tail movement. To improve the chances of logger recovery, only individuals with chicks less than $6 \mathrm{wk}$ of age were used. To balance sampling rate and battery life, the loggers were programmed to obtain a location every $90 \mathrm{~s}$ when penguins were at the surface. Penguins were recaptured in their burrows 1-5 d after initial logger deployment and the logger removed. Penguins were handled for less than 10 min during logger attachment and removal.

GPS locations were downloaded from loggers using @trip software (Mobile Action Technology) and formatted using custom scripts in the Python programming language (Python Core Team 2019). For penguins that completed multiple foraging trips during the logger attachment period, only the first foraging trip was used to maintain independence between observations. Descriptive trip statistics and metrics were extracted from the track data (trip duration, distance travelled and maximum displacement) using custom scripts in Python. Mean values of trip metrics were then statistically compared between colonies using ANOVA in the $\mathrm{R}$ programming language $(\mathrm{R}$ Core Team 2019) with the significance threshold set at 0.05 . Model assumptions were checked visually using diagnostic plots produced in $\mathrm{R}$.

To quantify how little penguins utilise their marine habitat, foraging trips were divided into 3 different behavioural states using a 3 state HMM for each colony based on relative turning angles (RTAs) and inter-fix step-length. The initial parameters for these behavioural states were selected in reference to previous work that identified 3 distinct behavioural states in little penguin at-sea movement patterns 
(Zhang et al. 2015). These states were (1) 'area restricted search' (ARS), characterised by small steplengths and a wide distribution of RTAs; (2) 'slowdirected', characterised by intermediate step-lengths and a narrow distribution of RTAs; and (3) 'fastdirected', characterised by larger step-lengths and a very narrow distribution of RTAs. Models were fit, using the same initial parameters for each colony, in the R package 'moveHMM' (Michelot et al. 2016b). HMMs were utilised due to their suitability for data with negligible measurement error (i.e. GPS-based location estimates) and flexibility to identify the complex correlation structure found in movement data (Michelot et al. 2016a). Time spent in each of these behavioural states was calculated for each colony and statistically compared using ANOVAs in R, with the significance threshold set at 0.05 . Time spent in each behavioural state was also compared using ANOVAs within each colony.

Because HMMs require a regular sampling unit (Michelot et al. 2016a), a continuous movement path was recreated using continuous-time correlated random walk models in the correlated random walk library (crawl) framework (Johnson 2016). The model was fit using a Kalman filter on a state-space version of the continuous-time stochastic movement process. This process produced regular track data, with positions at 10 min intervals. The 10 min interval was selected due to the temporal resolution of the environmental data (hourly). Trips had an average of 333 fixes prior to regularisation, which was reduced to 114 fixes on average post-regularisation. As crawl is optimised for use with ARGOS data, the model's error standard deviation was adjusted to be $\log (5) \mathrm{m}$ to account for the negligible error of GPS devices. One issue that arose from this is that the regularised continuous movement path would interpolate through gaps in the data (periods of time where no GPS fixes were obtained due to fast movement or diving activity), creating unrealistic movement paths that were completely straight and with uniform step lengths. To address this, any points in the continuous movement paths that were found to be within data gaps (identified by their unrealistically consistent velocities at each step) were replaced with missing values and were not considered by the HMM (the 'moveHMM' framework is able to handle missing values).

Environmental covariate data were obtained for each position in the state-spaced predicted movement path. These data were extracted from the Southeast Tasmania-Operational Hydrodynamic Model (SETAS) developed by the Commonwealth Scientific and Industrial Research Organisation (CSIRO) Coastal Environmental Modelling Team, which provides hourly observations of several environmental and hydrodynamic variables at grid resolutions ranging from 1.4-2.5 km over the Storm Bay region (Jones et al. 2012). Environmental variables extracted from SETAS were SST, salinity, bathymetry, current magnitude and sea surface height anomaly (Fig. 2). Mixed-layer depth was calculated from SETAS temperature-salinity profiles at the depth where an increase in density of $\Delta \sigma \mathrm{T}=0.125$ occurred relative to the surface layer. Wind data were obtained from
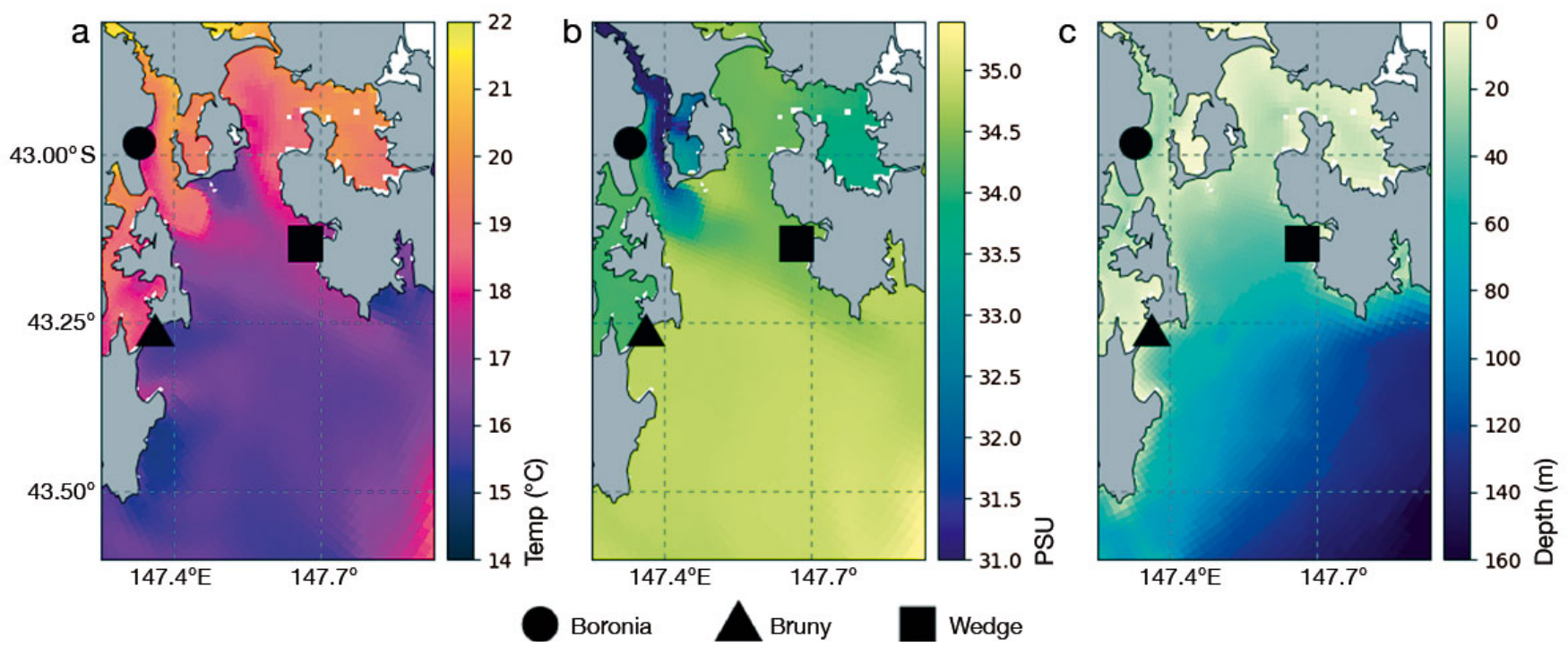

Fig. 2. Examples of data fields for the Storm Bay study region from the SETAS hydrodynamic model showing (a) sea surface temperature $\left({ }^{\circ} \mathrm{C}\right) ;(\mathrm{b})$ surface salinity (PSU); and (c) bathymetry (depth in $\mathrm{m}$ ) and the 3 little penguin colonies investigated in this study. Data snapshot is from 12:00 h, 25 December 2015 

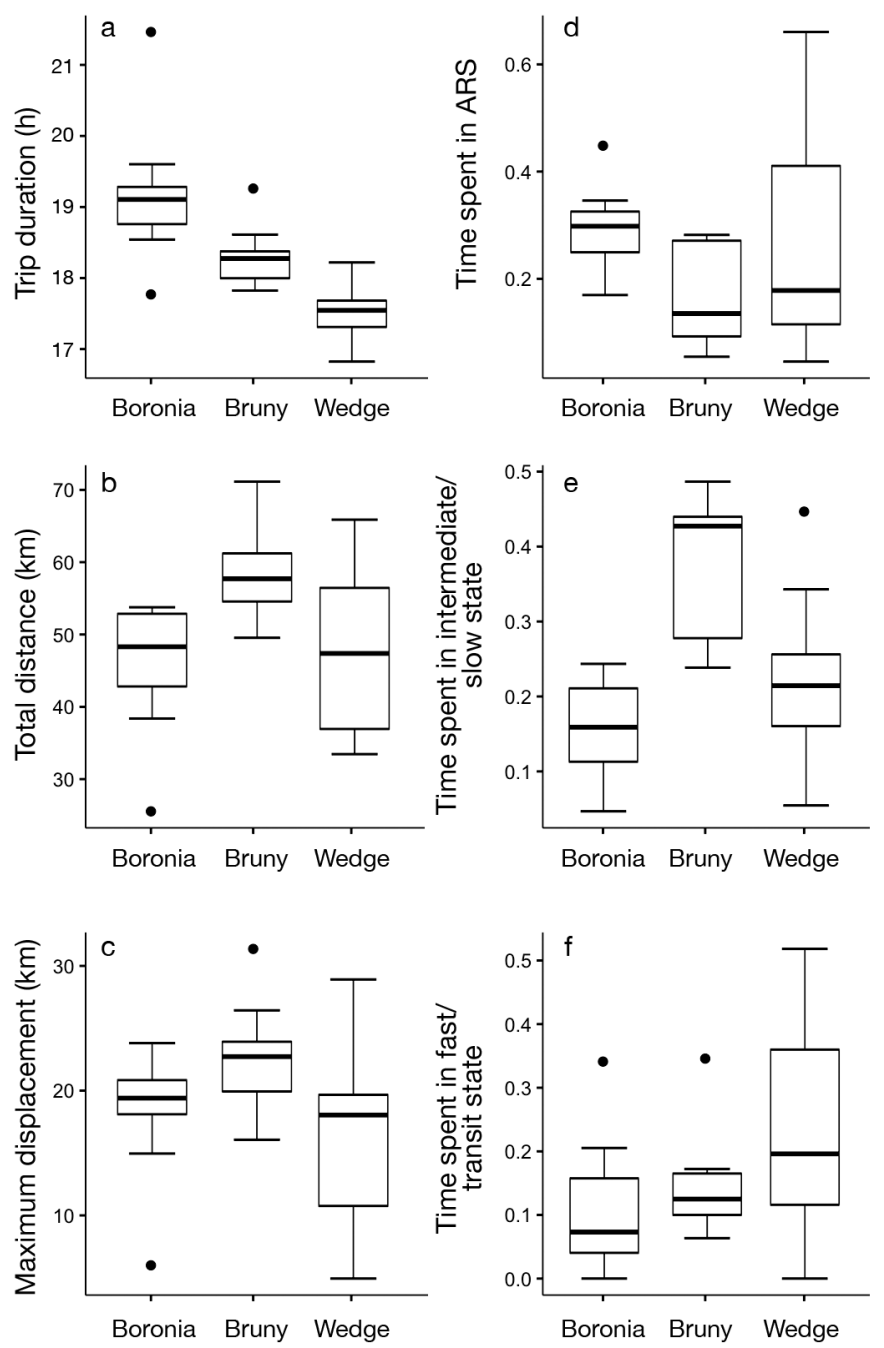

Fig. 3. Little penguin trip metrics (a) trip duration; (b) total distance travelled; (c) maximum displacement from colony; and total proportion of time spent in each of the behavioural states - (d) area restricted search (ARS); (e) intermediate/slow state; (f) fast/transit state for each of the study colonies. Boxes: the first to third quartile of the data; black line: median; box whiskers: minimum and maximum values; black dots: outliers

the Tasman Island weather station $\left(43.24^{\circ} \mathrm{S}\right.$, $148.00^{\circ} \mathrm{E}$ ) Bureau of Meteorology, Tasmania. The optimal environmental covariate formula for each colony was determined using forward selection stepwise regression based on Akaike's information criterion (AIC). The model selection algorithm was custom built using the R programming language (R Core Team 2019) and would continuously run the HMM with differing combinations of environmental covariate formulas until a global optimal model was found. The transitional probabilities of switching between behavioural states were then calculated for the selected covariate models of each colony.

\section{RESULTS}

A total of 29 little penguins were tagged at the 3 colonies between December 2015 and January 2016, with 8 individuals tagged at Boronia Beach, 9 at Bruny Island and 12 at Wedge Island. All foraging trips in the analysis were $<24 \mathrm{~h}$ in length, and there were substantial differences in little penguin foraging behaviour between the study colonies. All trip metrics varied significantly between colonies (Fig. 3, Table 1). The Boronia Beach colony had the longest trip duration (mean \pm SD: $19.2 \pm 1.0 \mathrm{~h}$ ) and Wedge Island, the shortest $(17.5 \pm 0.4 \mathrm{~h})$. Individuals from the Bruny Island colony travelled a greater total distance $(58.3 \pm 6.4 \mathrm{~km})$ and had a greater maximum displacement $(22.7 \pm 4.4 \mathrm{~km})$ relative to the other colonies (Table 2).

Significant inter-colony variation in the proportion of time spent in each behavioural state (ARS, slowdirected and fast-directed) was found only for the slow-directed state $\left(F_{2,24}=9.86, \mathrm{p}<0.001\right.$; Table 1$)$. Significant intra-colony variation in the proportion of time spent in each behavioural state was found within 2 of the colonies. Individuals from the Boronia Beach colony spent a large proportion of time at sea in $\operatorname{ARS}\left(F_{2,24}=7.82, \mathrm{p}=0.004 ;\right.$ Fig. 4$)$ and this state occurred in spatially concentrated regions (Fig. 5). Individuals from Bruny Island spent a greater proportion of their time at sea in the slow-directed state $\left(F_{2,24}=16.41, \mathrm{p}<0.001\right)$ and sporadic periods of time in ARS. Individuals from Wedge Island spread their time more uniformly between the 3 states $\left(F_{2,24}=\right.$

Table 1. Results of the ANOVAs comparing trip metrics between little penguin colonies, time spent in behavioural states (area-restricted search [ARS], slow-directed and fast-directed) between and within colonies. ${ }^{*}$ Statistically significant results

\begin{tabular}{|lrrr|}
\hline & df & F-value & $\mathrm{p}$ \\
\hline Inter-colony comparisons & & & \\
Metric & & & \\
Trip duration & 2 & 22.36 & $<0.001^{*}$ \\
Distance travelled & 2 & 4.820 & $0.017^{*}$ \\
Maximum displacement & 2 & 3.477 & $0.047^{*}$ \\
State & & & \\
ARS & 2 & 2.328 & $0.117^{*}$ \\
Slow-directed & 2 & 9.862 & $<0.001^{*}$ \\
Fast-directed & 2 & 1.665 & 0.209 \\
Within-colony state comparisons & & \\
Colony & & & \\
Boronia Beach & 2 & 7.482 & $0.004^{*}$ \\
Bruny Island & 2 & 16.41 & $<0.001^{*}$ \\
Wedge Island & 2 & 0.187 & 0.830 \\
\hline
\end{tabular}


Table 2. Colony-specific metrics of little penguin trip duration, total distance travelled and maximum displacement from the colony. Minimum, maximum and mean values are displayed. No. tracks: the number of individuals successfully tagged with GPS loggers at each location; deployment date range: the period in which loggers were deployed

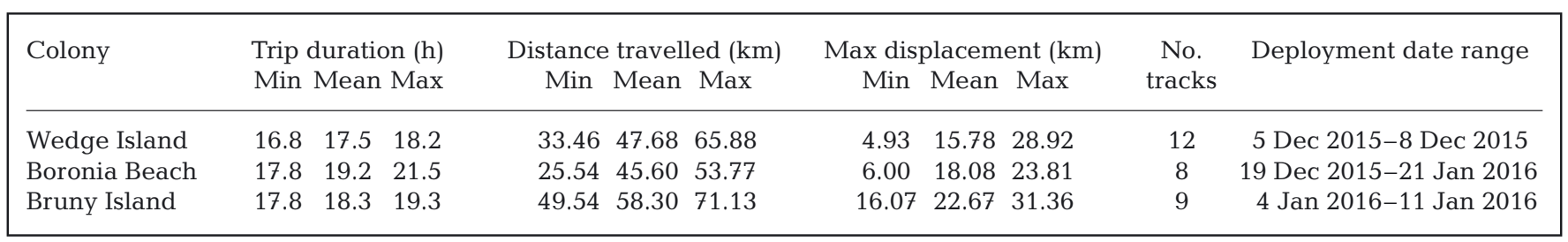

0.18, $\mathrm{p}=0.830$ ) but on visual inspection, there appeared to be 2 clear behavioural foraging strategies within this colony. Strategy 1 was observed in 4 individuals and was characterised by trips with lower maximum displacement, primarily in ARS in concentrated regions to the northwest of the colony (Fig. 5). Strategy 2 was observed in 8 individuals and consisted of trips of higher maximum displacement with more sporadic periods of time spent in ARS (Fig. 4) and a relatively high proportion spent in a fastdirected state (Fig. 4) south of the colony. A linear regression model was used to investigate these strategies against wind-speed data from the Bureau of Meteorology, with Strategy 2 being found to be more probable during periods of greater maximum gust speeds $\left(F_{1,10}=10.89, \mathrm{p}=0.008\right)$.

The stepwise model selection process indicated that transitions between behavioural states were more highly influenced by different environmental variables at each colony. Behavioural state transition probabilities were a function of depth for Boronia Beach individuals, sea surface height anomaly for Bruny Island individuals and salinity and SST for Wedge Island birds. Fast-directed travel for Boronia a) Boronia state sequences
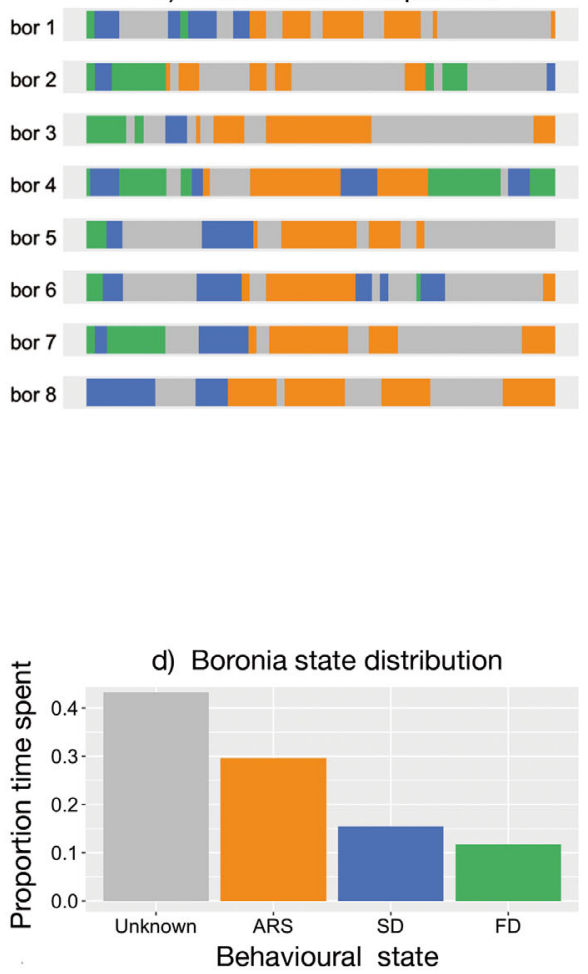

b) Bruny state sequences

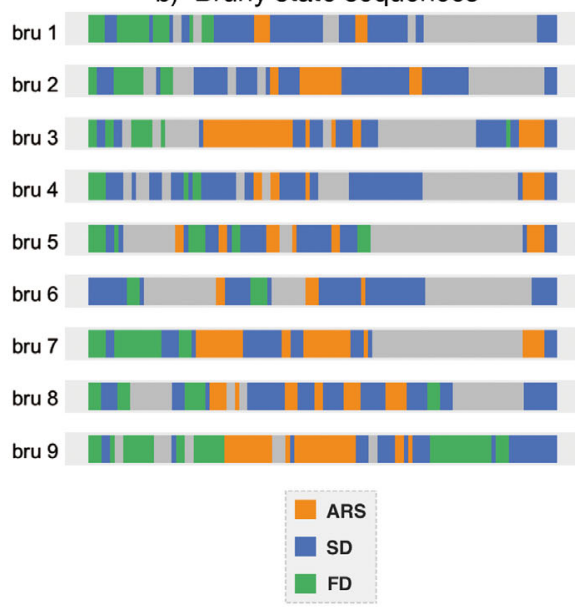

e) Bruny state distribution

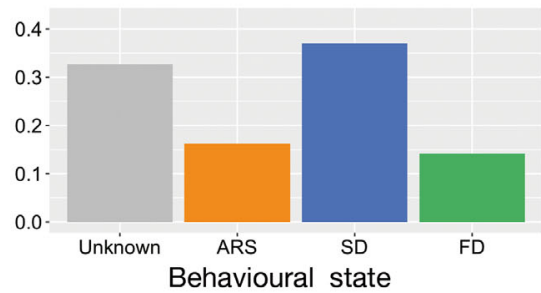

c) Wedge state sequences

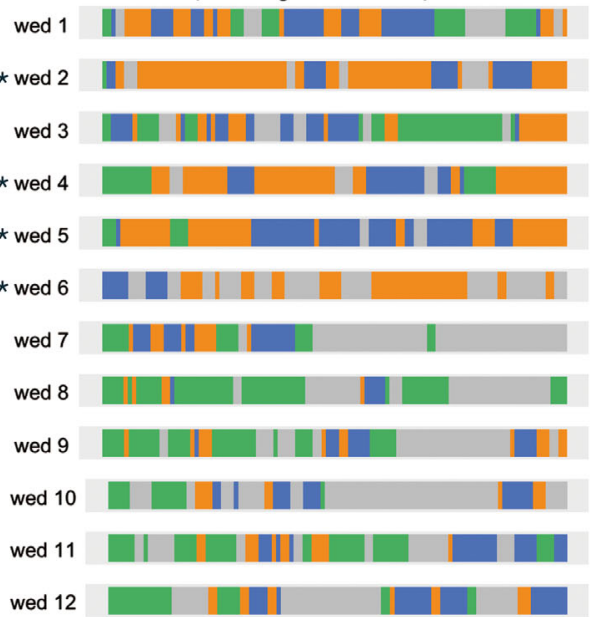

f) Wedge state distribution

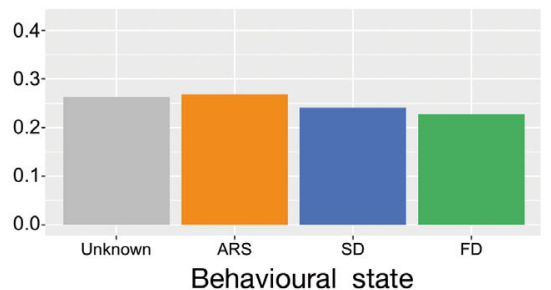

Fig. 4. (a-c) Time series of behavioural states inferred from hidden Markov model analysis for each of the GPS-tagged little penguins at each colony. Grey (unknown): missing values where there is no known state or position. (d-f) Total proportion of time spent in each behavioural state for each of the study colonies. Behavioural states are denoted by colour: area-restricted search (ARS), slow-directed (SD) and fast-directed (FD). For Wedge Island, 2 different foraging strategies were noted. Strategy

1 is denoted by an asterisk $(*)$ 


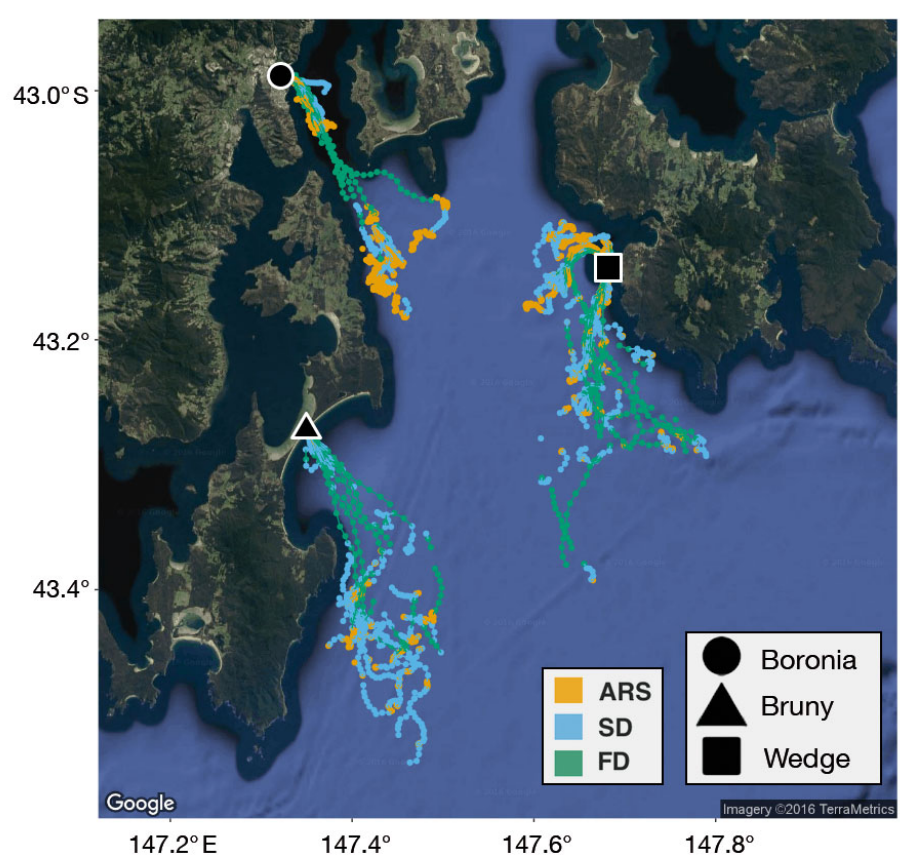

Fig. 5. Regularised little penguin GPS tracks overlaid on satellite imagery of Storm Bay, Tasmania, Australia. Behavioural states are denoted by colour: area-restricted search (ARS), slow-directed (SD) and fast-directed (FD). Points that were regularised through gaps in GPS fixes were dropped. Satellite imagery obtained from Google Earth (http://earth. google.com)

Beach individuals was only associated with shallower waters, while ARS and slow-directed travel took place in both shallow and deeper waters. Furthermore, the transition probabilities revealed that penguins at Boronia Beach were more likely to change from fast-directed $\rightarrow$ slow-directed and slowdirected $\rightarrow$ ARS states as depth increased (Fig. 6). The fast-directed state for Bruny Island birds showed a clear association with positive values of sea surface height anomaly (Fig. 7a) while slow-directed travel was associated with negative values of sea surface height anomaly. Bruny Island birds also had a higher probability of transitioning between states (i.e. slowdirected $\leftrightarrow$ fast-directed) with positive sea surface height anomaly values and from ARS $\rightarrow$ slow-directed with negative values (Fig. 6). To check the association of tidal flow with penguin travelling direction at Bruny Island, trips were divided into outbound (period before point of maximum displacement from colony) and inbound (period after point of maximum displacement from colony). The change in sea surface height anomaly over these trip periods was also calculated. Outbound trips were found to be associated with a negative change in sea surface height anomaly and, conversely, inbound trips were associ- ated with a positive change in sea surface height anomaly $\left(F_{1,16}=38.86, \mathrm{p}<0.001\right)$, indicative of outward and inward tidal flow respectively.

For the Wedge Island birds, the fast-directed state was associated with waters of high salinity, low temperature values while slow-directed state and ARS were associated with lower salinity and warmer water. The probability of switching from slowdirected $\rightarrow$ ARS states greatly increased in less saline, cooler water and, conversely, the probability of moving from ARS $\rightarrow$ slow-directed was greater in higher saline, warmer waters. A transition from fastdirected $\rightarrow$ slow-directed was slightly more probable in lower saline, warm waters (Fig. 6).

\section{DISCUSSION}

This study revealed fine-scale differences in foraging behaviour related to variable environmental features for individuals from 3 little penguin colonies in southern Tasmania. Despite the relatively close proximity of the colonies (<33 km apart), foraging behaviour was found to correspond to different environmental factors at each colony, and there were substantial differences in at-sea behaviour among birds from the different colonies. Furthermore, the identified preferred foraging distributions and their environmental determinants revealed ecologically important zones of potential high prey abundance. The locations of these zones may be driven by exposure to wind and wave forcing mechanisms which break down stratification and replenish nutrients into the system and/or create dense aggregations of prey species (Harris et al. 1988, 1991, 1992). This flexibility in behaviour is consistent with previous work showing that little penguins adjust their foraging energy and activity budgets in response to variability in local environmental conditions (Berlincourt \& Arnould 2015, Kowalczyk et al. 2015, Saraux et al. 2016). In our study, this was evident at a much finer spatial scale.

Wedge Island penguins were found to have shorter trip durations, and Boronia Beach penguins the longest. Individuals from Bruny Island typically travelled much further in terms of total distance travelled and maximum displacement from the colony. Variability in distance travelled was equivalent to studies in other regions (Pelletier et al. 2014, Berlincourt \& Arnould 2015). Penguins from Bruny Island spent a considerable proportion of time at sea in the slowdirected behavioural state beginning immediately after leaving the more sheltered region of Adventure 


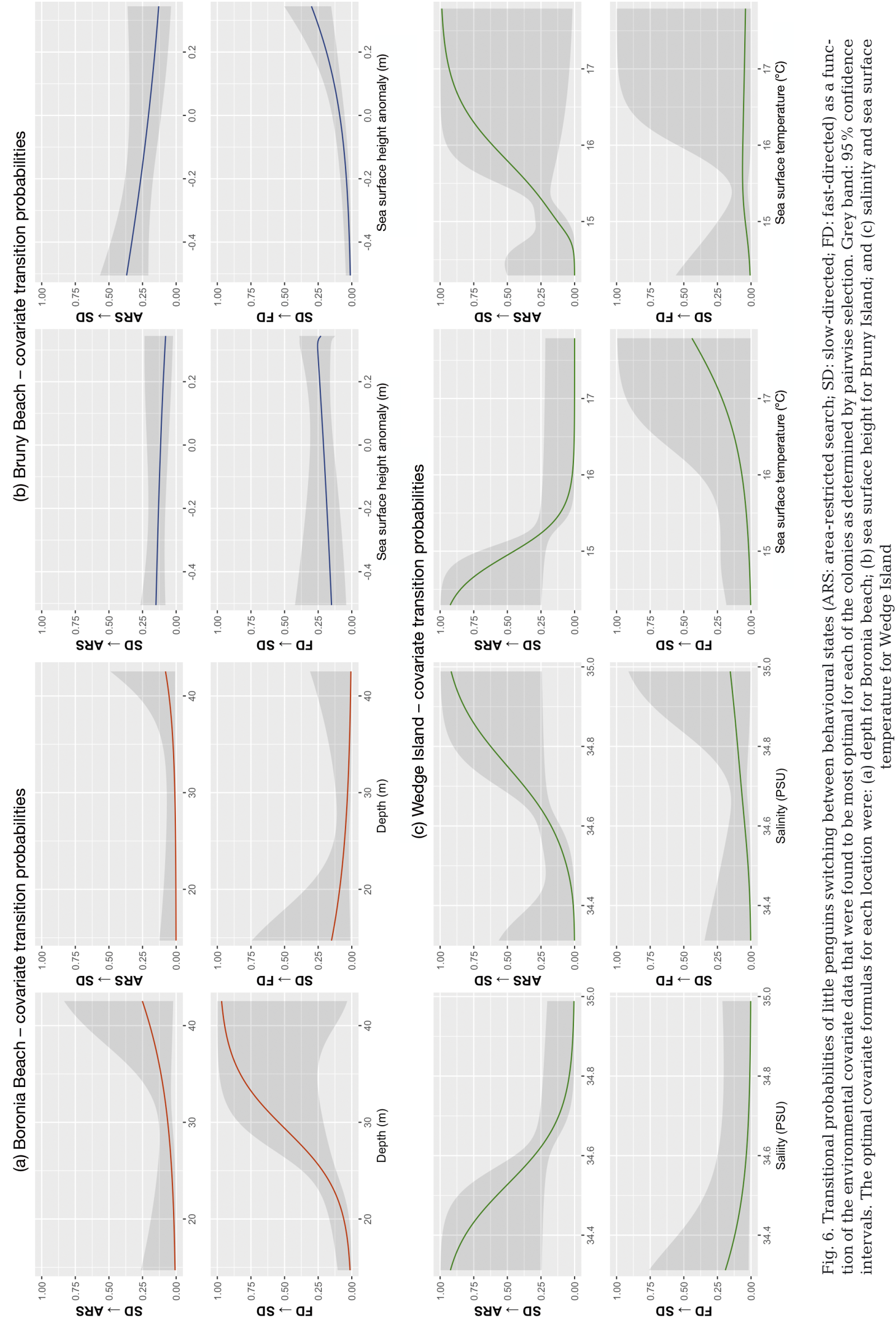



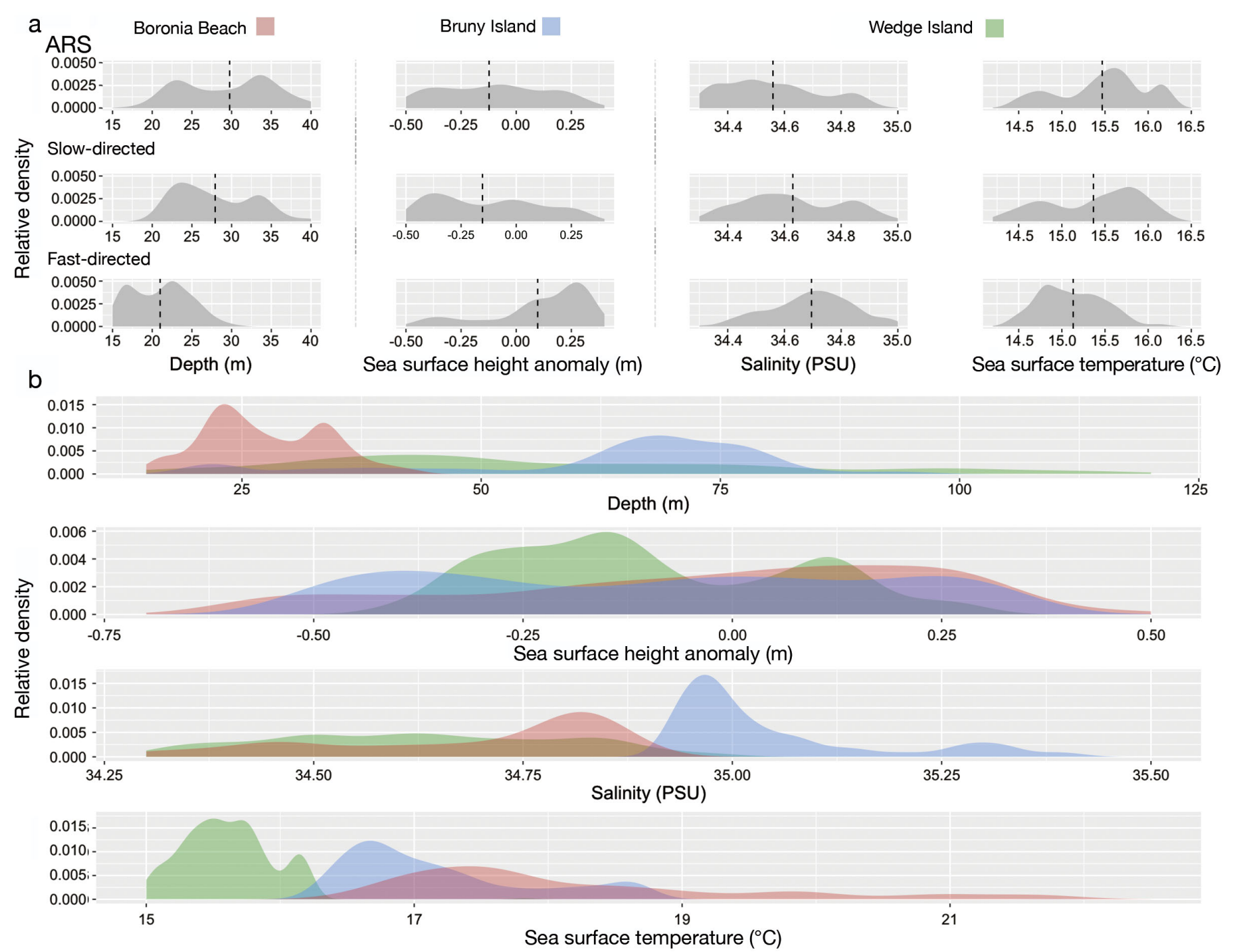

Fig. 7. Density plots showing (a) density distribution of the environmental parameters encountered by little penguins in each behavioural state (area-restricted search [ARS], slow-directed and fast-directed) for the optimal covariate models (dotted vertical lines depict the mean values) and (b) full range of environmental parameters encountered by all tagged individuals for each colony

Bay (Fig. 5). While ARS is a likely indicator of foraging activity, it is quite likely that foraging activity is also taking place in the slow-directed behavioural state. This may be a consequence of the hierarchical clustering effect of prey species. Carroll et al. (2017) found a bimodal distribution in the time between little penguin prey capture events at Montague Island, implying that foraging behaviour occurs on multiple spatial scales corresponding to within- and between-patch movements. Consequently, the ARS and slow-directed states may correspond to within- and between-patch movements, respectively. The fact that the majority of ARS and slow-directed behaviour was observed in the exposed region outside Adventure Bay (Fig. 5) suggests that the individuals at Bruny Island favour this area for foraging purposes (Fig. 5).
There was a strong association between fastdirected movement and sea surface height anomaly and, additionally, outbound and inbound trips were correlated with negative and positive changes in sea surface height anomaly, respectively. It is commonly assumed that animals adopt strategies to maximise the ratio of energy gained to energy expended (Charnov 1976), of which locomotion has been shown to be a major cost (Ware et al. 2016). Given the additional distances Bruny Island penguins travelled to their foraging area, these penguins may be utilising tidal currents during fast-directed movement to increase their speed without expending additional energy. Negative sea surface height anomaly has also been found to be associated with marine predator foraging behaviour in other species such as ele- 
phant seals (Tosh et al. 2015). This is hypothesised to be because negative values of sea surface height anomaly are associated with environmental features such as cold core eddies, which bring nutrients to the surface. This phenomenon, however, takes place on scales much larger than those discussed here but it is possible that similar features may exist at scales relevant to little penguins, such as eddies or frontal boundaries (Grecian et al. 2018).

Penguins from Bruny Island favoured southern oceanic waters for foraging purposes rather than the immediately adjacent waters of Adventure Bay. This may be attributable to Adventure Bay's more sheltered position from wind and wave exposure (predominantly from the southwest) as a consequence of the blocking action of Bruny Island (Barrett et al. 2001). A number of studies have documented how varying wind regimes in Storm Bay induce localised wind and wave action that breaks down the stratification of the water column, resulting in an influx of cool, nutrient-rich water into the system (Harris et al. 1987, 1988, 1991, 1992, Clementson et al. 1989). This physical mechanism provides ecological, bottom-up control at a local level, resulting in patches of high prey abundance (Harris et al. 1991). Conversely, calmer periods in Storm Bay with reduced windforced mixing and higher stratification led to highly oligotrophic conditions and the subsequent elimination of larger zooplankton species such as the euphasiid Nyctiphanes australis (a prey species of little penguins and small pelagic fishes) and a shift towards small copepods (Harris et al. 1991). In the summer of 1988-1989, this phenomenon led to a collapse of the jack mackerel Trachurus declivis fishery in Tasmania (Harris et al. 1991). This is at odds with the results of studies from Phillip Island, where a reduction in thermal stratification was associated with a reduction in little penguin foraging efficiency and breeding success (Ropert-Coudert et al. 2009, Pelletier et al. 2012). Consequently, this may be a highly localised phenomenon that little penguins in Storm Bay may be exploiting at fine spatial scales.

Wind-forced processes may also be relevant at Wedge Island, where 2 distinct foraging strategies were identified: (1) short distance trips, $4-11 \mathrm{~km}$ to the northwest of the colony with penguins spending a larger proportion of the foraging trip in ARS and (2) longer distance trips, $14-29 \mathrm{~km}$ to the south with relatively little time spent in ARS. The latter coincided with periods of high maximum wind gust speeds, which increased from $35-39 \mathrm{~km} \mathrm{~h}^{-1}$ SSE to $72-85 \mathrm{~km}$ $\mathrm{h}^{-1}$ NNE over the tracking period. The presence of 2 behavioural strategies at this colony would explain the greater variance in trip metrics observed at this colony (Fig. 3). Previous studies have shown sitespecific relationships between wind speed and foraging behaviour (Lea et al. 2009, Berlincourt \& Arnould 2015, Saraux et al. 2016). For example, at Phillip Island, Victoria, Australia, Saraux et al. (2016) demonstrated a negative relationship between wind speed and foraging success, attributed to disruption of the thermocline and swell formation. Ganendran et al. (2011), also at Phillip Island, considered the impacts of wind direction on little penguin survival and found a positive relationship with southerly winds, which transport relatively cold, nutrient-rich water from Bass Strait. In our study region, there have been anecdotal reports of high concentrations of $N$. australis following periods of stronger winds (Palmer 1978), providing a potential zone of prey aggregation for penguins. The absence of this ecological incentive during calmer periods may also explain why the penguins were less likely to make the longer southward foraging trips during these periods.

In our study, changes between behavioural states were associated with different environmental parameters at each of the study colonies: at Boronia Beach, behavioural states associated with water depth; at Bruny Island, with sea surface height (tidal flow); and at Wedge Island, SST and salinity. This suggests that localised, fine-scale environmental variability may induce different behavioural responses among penguin colonies, with each colony utilising different strategies to optimise foraging success. Penguins from Boronia Beach spent a large proportion of the foraging trip in ARS and typically moved quickly out of the Derwent Estuary, concentrating foraging efforts at the river mouth in relatively deeper waters. Foraging trip duration was notably longer at this location during the logger deployment period. Concentration of foraging effort around river mouths is a frequently observed behaviour in seabirds (Kowalczyk et al. 2015). This is because river plumes contain high quantities of nutrients known to aggregate planktonic organisms that in turn attract and sustain schools of planktivorous fish (Kudela et al. 2010). Boronia Beach penguins may be exploiting this resource.

Although the Boronia Beach penguins spent considerable time in ARS, this does not necessarily equate to foraging success. Considering the longer trip durations and concentrated foraging zone, this may indicate an increase in foraging effort (Berlincourt \& Arnould 2015) owing to less abundant prey and/or increased competition (Angel et al. 2016). Furthermore, ARS is a highly energy-intensive behavioural state. Measurements of energy expenditure in king pen- 
guins Aptenodytes patagonicus, derived from heartrate loggers, showed that ARS behaviour was much more energy-intensive than long fast-directed movement (Froget et al. 2004). It is possible that the observed foraging location of the Boronia Beach colony penguins reflects greater foraging effort compared to birds from the other colonies considered in this study. Conversely, the time spent in ARS could indicate an abundance of concentrated prey in the region the individuals are exploiting. The high proportion of time spent in ARS could be a consequence of penguins needing to rest after prey-capture events due to digestion capabilities which would mimic the ARS behaviour, inflating the results. Additional research is required to resolve this uncertainty, which could be achieved through the use of additional logging devices such accelerometers to obtain prey-capture data (Carroll et al. 2016).

Penguins from the Wedge Island colony were more likely to change from the slow-directed state to ARS in cooler, less saline waters. Conversely, they transitioned from ARS to the slow-directed state in warmer, more saline waters. The former conditions are typical of upwellings due to localised mixing events (Harris et al. 1988, 1992) and the episodic influxes of nutrient-rich subantarctic waters that are driven in summer by the erratic offshore eddy field associated with the EAC (Ridgway 2007). Such conditions are preferred by the euphausiid N. australis, which favours cooler, less saline waters (Harris et al. 1991, Kelly et al. 2016). N. australis is an important component of pelagic food webs, supporting many species such as small pelagic fishes and other commercially important fisheries (Palmer 1978, Ritz \& Hosie 1982, McLeod et al. 2012). Considering this trophic relationship, conditions that are favourable to $N$. australis would likely result in aggregations of small pelagic fishes, which are the primary dietary component of little penguins in Storm Bay (Gales \& Pemberton 1990, Eberle 2003). Furthermore, little penguins have been observed to also prey on $N$. australis, particularly in the absence of alternative higher-order prey (Gales \& Pemberton 1990, Eberle 2003, Wiebkin 2012). Thus, these cooler, less saline waters may represent preferable foraging conditions, explaining the switch to ARS behaviour. Carroll et al. (2016) similarly found that little penguins at Montague Island, New South Wales, Australia, had reduced prey capture success in years with aboveaverage SST. Likewise, African penguins Spheniscus demersus, which have a similar diet, avoid warm water intrusions in favour of cooler upwelling areas (van Eeden et al. 2016).
This finding of inter-colony behavioural variability at fine spatial scales has important implications for colony-based seabird studies. For instance, findings of long-term longitudinal studies focusing on single colonies may not be representative of all colonies, and thus may underestimate flexibility in response to environmental variation. However, results from this cross-colony study of little penguin foraging behaviour from one breeding season are also potentially confounded with minor differences in the timing of GPS-logger deployment relative to breeding stage at each colony. Little penguin foraging behaviour is influenced by multiple extrinsic factors such as site location and breeding/clutch stage (Camprasse et al. 2017). Therefore, it is difficult to say to what degree the variability in foraging behaviour identified in this study was determined by spatial environmental variability and what may be attributable to differences in the breeding/clutch stage. However, the onset of the little penguins' reproduction at Phillip Island is correlated with local SSTs and consistently coincides with the peak period of ocean productivity (Afán et al. 2015). This correlation would make decoupling the effect of environmental variability and breeding stage on foraging behaviour a difficult undertaking. Additionally, the difference in timing of logger deployment between colonies may be particularly significant within a system as variable as Storm Bay. Notably, individuals at Bruny Island experienced relatively more saline conditions than the other colonies (Fig. 7b), which may indicate a change in oceanic character in the bay due to the intensification of the 2015-2016 marine heatwave event (Oliver et al. 2017). Deploying loggers at multiple locations simultaneously would reduce this uncertainty. We were unable to implement this in the present study owing to logistical constraints and because the little penguin breeding season is highly asynchronous in Tasmania (Stevenson \& Woehler 2007).

In our study there were 'gaps' present in the GPS records where the GPS logging device was unable to obtain a positional fix owing to either high movement speed or diving activity (Fig. 4). This could potentially influence the results of this study, as the analysis is not based on a complete record of behavioural activity for each individual. These gaps are common in little penguin tracking studies and are commonly associated with transiting behaviour (Carroll et al. 2017). A study at Montague Island found that $<8 \%$ of prey-capture events by penguins actually occurred during gaps that were greater than 5 min in length, and therefore may generally reflect periods when the penguins are travelling between locations, rather 
than when they are spending a lot of time submerged during active foraging (Carroll et al. 2017). Thus, we do not believe that the presence of gaps in our study would significantly alter our findings.

Ideally, longitudinal studies of multiple colonies are needed to account for localised spatial variability in environmental parameters. This is difficult, however, owing to logistical and funding barriers. Future work should also consider the use of additional biologging devices to further quantify little penguin foraging behaviour. For instance, the implementation of accelerometers (Carroll et al. 2016) and/or animalborne cameras (Sutton et al. 2015, Mattern at al. 2018) would provide a direct measurement of preycapture events, while use of heart-rate loggers would provide data on energy expenditure and, consequently, foraging effort (Froget et al. 2004). The use of additional logging devices would assist in quantifying foraging behaviour that occurs during large 'data gaps'. Furthermore, the establishment of regular colony surveys of population metrics and breeding success would prove useful for testing hypotheses on the effectiveness of alternative foraging strategies and the fitness impacts of environmental variability (Berlincourt \& Arnould 2015, Kowalczyk et al. 2015, Saraux et al. 2016).

Short-duration studies may also occur in periods that differ from typical conditions. Indeed, over this study period, Storm Bay experienced the longest and most intense marine heatwave on record (Oliver et al. 2017), which significantly altered the oceanic character of the bay. Modelling indicates that extreme event likelihoods will increase in the future, owing to increasing anthropogenic influences and further EAC intensification (Oliver et al. 2017). This is concerning given the importance of the cold, nutrient-rich waters for determining prey fields in the bay (Harris et al. 1991). Furthermore, reduced prey-capture success for little penguins during periods of warmer oceanic conditions has also been reported for colonies in southern New South Wales (Carroll et al. 2016). Correlations between anomalously high SST and the availability of pelagic fishes has been observed in other western-boundary systems. In the Sea of Japan, which is influenced by the warm Kuroshio Current, sardine catches are lowest during periods of high SST (Yasuda et al. 1999). High SST has also been observed to increase mortality (Nishikawa \& Yasuda 2008) and lower recruitment (Lindegren \& Checkley 2013) of juvenile sardines. In Tasmania, large-scale shifts in species distribution and community structure are related to southward extension of the warm EAC (Johnson et al. 2011,
McLeod et al. 2012, Buchanan et al. 2014), which may negatively impact fish predators in south-eastern Tasmanian waters.

Although little penguins are variable and adaptable in their foraging behaviour, these individual strategies are not always sufficient to cope with changes in environmental conditions (Berlincourt \& Arnould 2015), and the limits to this adaptability are unknown. Therefore, observations of short-term behavioural adaptation to environmental change by little penguins should not necessarily be interpreted as a sign of longer-term resilience to such changes. A critical next research step is to identify the scope of this flexibility and determine potential thresholds beyond which behavioural patterns cannot compensate for environmental changes. Continued monitoring of little penguin movement patterns will reveal if colony behaviours are fixed or plastic and provide insight into the potential implications of continued warming for the Storm Bay ecosystem, which is a natural laboratory for rapidly changing regions (Pecl et al. 2014).

Acknowledgements. We are grateful for the assistance of volunteers who helped with the fieldwork (Alexa Hasselman, Luke Budd, Tommy Males and Patrick Scharf), Théo Michelot for his guidance in implementing hidden Markov models in the analysis and Natalie Bool for her assistance with the Wedge Island fieldwork. All animal research protocols were carried out in accordance with guidelines approved by the University of Tasmania Animal Ethics Committee (Permit Number: A0014186) and the Department of Primary Industries, Parks, Water and Environment (DPIPWE) (Authority No. FA 15220). The little penguin GPS track data are open access and available through the Institute for Marine and Antarctic Studies (IMAS) data portal (https://data.imas.utas. edu.au/) and via the Ocean Biogeographic Information System (OBIS) data portal (https://obis.org/).

\section{LITERATURE CITED}

Afán I, Chiaradia A, Forero MG, Dann P, Ramírez F (2015) A novel spatiotemporal scale based on ocean currents unravels environmental drivers of reproductive timing in a marine predator. Proc R Soc B 282:20150721

Angel LP, Berlincourt M, Arnould JPY (2016) Pronounced inter-colony variation in the foraging ecology of Australasian gannets: influence of habitat differences. Mar Ecol Prog Ser 556:261-272

Ballard G, Dugger KM, Nur N, Ainley DG (2010) Foraging strategies of Adélie penguins: adjusting body condition to cope with environmental variability. Mar Ecol Prog Ser 405:287-302

Barrett NS, Sanderson JC, Lawler M, Halley V, Jordan A (2001) Mapping of inshore marine habitats in south-eastern Tasmania for marine protected area planning and marine management. Tasmanian Aquaculture and Fisheries Institute, Taroona 
Benoit-Bird KJ, Battaile BC, Nordstrom CA, Trites AW (2013) Foraging behavior of northern fur seals closely matches the hierarchical patch scales of prey. Mar Ecol Prog Ser 479:283-302

Berlincourt M, Arnould JPY (2015) Influence of environmental conditions on foraging behaviour and its consequences on reproductive performance in little penguins. Mar Biol 162:1485-1501

* Buchanan PJ, Swadling KM, Eriksen RS, Wild-Allen K (2014) New evidence links changing shelf phytoplankton communities to boundary currents in southeast Tasmania. Rev Fish Biol Fish 24:427-442

Camprasse ECM, Sutton GJ, Berlincourt M, Arnould JPY (2017) Changing with the times: little penguins exhibit flexibility in foraging behaviour and low behavioural consistency. Mar Biol 164:169

Carroll G, Everett J, Harcourt R, Slip D, Jonsen I (2016) High sea surface temperatures driven by a strengthening current reduce foraging success by penguins. Sci Rep 6: 22236

Carroll G, Cox M, Harcourt R, Pitcher BJ, Slip D, Jonsen I (2017) Hierarchical influences of prey distribution on patterns of prey capture by a marine predator. Funct Ecol 31:1750-1760

Charnov EL (1976) Optimal foraging, the marginal value theorem. Theor Popul Biol 9:129-136

* Clementson L, Harris G, Griffiths F, Rimmer D (1989) Seasonal and interannual variability in chemical and biological parameters in Storm Bay, Tasmania. I. Physics, chemistry and the biomass of components, of the food chain. Mar Freshw Res 40:25-38

Cresswell GR (2000) Currents of the continental shelf and upper slope of Tasmania. Pap Proc R Soc Tasman 133: 21-30

Eberle A (2003) An investigation into the diet of little penguins, Eudyptula minor, and short-tailed shearwaters, Puffinus tenuirostris, in south east Tasmania. PhD thesis, University of Tasmania, Hobart

Freitas C, Kovacs KM, Lydersen C, Ims RA (2008) A novel method for quantifying habitat selection and predicting habitat use. J Appl Ecol 45:1213-1220

Froget G, Butler PJ, Woakes AJ, Fahlman A, Kuntz G, Le Maho Y, Handrich Y (2004) Heart rate and energetics of free-ranging king penguins (Aptenodytes patagonicus). Exp Biol 207:3917-3926

Frusher SD, Hobday AJ, Jennings SM, Creighton C and others (2014) The short history of research in a marine climate change hotspot: from anecdote to adaptation in south-east Australia. Rev Fish Biol Fish 24:593-611

Gales R, Pemberton D (1990) Seasonal and local variation in the diet of the little penguin, Eudyptula minor, in Tasmania. Aust Wildl Res 17:231-259

Ganendran LB, Sidhu LA, Catchpole EA, Dann P, Chambers LE (2011) The effect of directional wind components on survival of little penguins Eudyptula minor. ANZIAM J 52:C1012-C1030

*Grecian WJ, Lane JV, Michelot T, Wade HM, Hamer KC (2018) Understanding the ontogeny of foraging behaviour: insights from combining marine predator bio-logging with satellite-derived oceanography in hidden Markov models. J R Soc Interface 15:20180084

Gurarie E, Bracis C, Delgado M, Meckley TD, Kojola I, Wagner CM (2016) What is the animal doing? Tools for exploring behavioural structure in animal movements. J Anim Ecol 85:69-84
Harris G, Nilsson C, Clementson L, Thomas D (1987) The water masses of the east coast of Tasmania: seasonal and interannual variability and the influence on phytoplankton biomass and productivity. Mar Freshw Res 38:569-590

* Harris GP, Davies P, Nunez M, Meyers G (1988) Interannual variability in climate and fisheries in Tasmania. Nature 333:754-757

Harris G, Griffiths F, Clementson L, Lyne V, Doe HD (1991) Seasonal and interannual variability in physical processes, nutrient cycling and the structure of the food chain in Tasmanian shelf waters. J Plankton Res 13:109-131

* Harris GP, Griffiths FB, Clementson LA (1992) Climate and the fisheries off Tasmania - interactions of physics, foodchains and fish. S Afr J Mar Sci 12:585-597

*Holling CS (1973) Resilience and stability of ecological systems. Annu Rev Ecol Syst 4:1-23

Ishak NA (2014) The bloom dynamics and trophic ecology of salps and doliolids in Storm Bay, Tasmania. PhD thesis, University of Tasmania, Hobart

* Johnson CR, Banks SC, Barrett NS, Cazassus F and others (2011) Climate change cascades: shifts in oceanography, species' ranges and subtidal marine community dynamics in eastern Tasmania. J Exp Mar Biol Ecol 400:17-32

Johnson DS (2016) crawl: fit continuous-time correlated random walk models to animal movement data. $\mathrm{R}$ package version 2.0.1

Jones EM, Oke PR, Rizwi F, Murray LM (2012) Assimilation of glider and mooring data into a coastal ocean model. Ocean Model 47:1-13

Kappes MA, Shaffer SA, Tremblay Y, Foley DG and others (2010) Hawaiian albatrosses track interannual variability of marine habitats in the North Pacific. Prog Oceanogr 86:246-260

Kelly P, Clementson L, Davies C, Corney S, Swadling K (2016) Zooplankton responses to increasing sea surface temperatures in the southeastern Australia global marine hotspot. Estuar Coast Shelf Sci 180:242-257

Kowalczyk ND, Reina RD, Preston TJ, Chiaradia A (2015) Environmental variability drives shifts in the foraging behaviour and reproductive success of an inshore seabird. Oecologia 178:967-979

Kudela RM, Horner-Devine AR, Banas NS, Hickey BM and others (2010) Multiple trophic levels fueled by recirculation in the Columbia River plume. Geophys Res Lett 37 : L18607

พ Langrock R, King R, Matthiopoulos J, Thomas L, Fortin D, Morales JM (2012) Flexible and practical modeling of animal telemetry data: hidden Markov models and extensions. Ecology 93:2336-2342

Lea MA, Johnson D, Ream R, Sterling J, Melin S, Gelatt T (2009) Extreme weather events influence dispersal of naive northern fur seals. Biol Lett 5:252-257

KLindegren M, Checkley DM Jr (2013) Temperature dependence of Pacific sardine Sardinops sagax recruitment in the California current ecosystem revisited and revised. Can J Fish Aquat Sci 70:245-252

Mannocci L, Boustany AM, Roberts JJ, Palacios DM and others (2017) Temporal resolutions in species distribution models of highly mobile marine animals: recommendations for ecologists and managers. Divers Distrib 23: 1098-1109

Mattern T, Ellenberg U, Houston DM, Lamare M, Davis LS, van Heezik Y, Seddon PJ (2013) Straight line foraging in yellow-eyed penguins: new insights into cascading fisheries effects and orientation capabilities of marine 
predators. PLOS ONE 8:e84381

Mattern T, McPherson MD, Ellenberg U, van Heezik Y, Seddon PJ (2018) High definition video loggers provide new insights into behaviour, physiology, and the oceanic habitat of marine top predators. PeerJ 6:e5459

McLeod DJ, Hobday AJ, Lyle JM, Welsford DC (2012) A prey-related shift in the abundance of small pelagic fish in eastern Tasmania? ICES J Mar Sci 69:953-960

Michelot T, Langrock R, Patterson TA (2016a) moveHMM: an $\mathrm{R}$ package for the statistical modelling of animal movement data using hidden Markov models. R package version 1.2

Michelot T, Langrock R, Patterson TA (2016b) movehmm: an $\mathrm{R}$ package for the statistical modelling of animal movement data using hidden Markov models. Methods Ecol Evol 7:1308-1315

Nishikawa H, Yasuda I (2008) Japanese sardine Sardinops melanostictus mortality in relation to the winter mixed layer depth in the Kuroshio extension region. Fish Oceanogr 17:411-420

Oliver ECJ, Perkins-Kirkpatrick SE, Holbrook NJ, Bindoff NL (2017) Anthropogenic and natural influences on record 2016 marine heat waves. Bull Am Meteorol Soc (Suppl)99:S54-S59

Palmer JW (1978) Concentrations of the krill Nyctiphanes australis G.O. Sars, 1883 (Euphausiacea) in Storm Bay and environs, south east Tasmania. Honours thesis (BSc), University of Tasmania, Hobart

Papastamatiou YP, DeSalles PA, McCauley DJ (2012) Arearestricted searching by manta rays and their response to spatial scale in lagoon habitats. Mar Ecol Prog Ser 456: 233-244

Patterson TA, Parton A, Langrock R, Blackwell PG, Thomas L, King R (2017) Statistical modelling of animal movement: an overview of key methods and a discussion of practical challenges. AStA Adv Stat Anal 101:399-438

* Pecl GT, Hobday AJ, Frusher S, Sauer WHH, Bates AE (2014) Ocean warming hotspots provide early warning laboratories for climate change impacts. Rev Fish Biol Fish 24:409-413

Pelletier L, Kato A, Chiaradia A, Ropert-Coudert Y (2012) Can thermoclines be a cue to prey distribution for marine top predators? A case study with little penguins. PLOS ONE 7:e31768

Pelletier L, Chiaradia A, Kato A, Ropert-Coudert Y (2014) Fine-scale spatial age segregation in the limited foraging area of an inshore seabird species, the little penguin. Oecologia 176:399-408

Pollard R, Bathmann U, Dubischar C, Read J, Lucas M (2002) Zooplankton distribution and behaviour in the Southern Ocean from surveys with a towed optical plankton counter. Deep Sea Res II 49:3889-3915

Python Core Team (2019) Python: a dynamic, open source programming language, version 3.6.8. Python Software Foundation, Wilmington, DE

R Core Team (2019) R: a language and environment for statistical computing. R Foundation for Statistical Computing, Vienna

Ridgway KR (2007) Long-term trend and decadal variability of the southward penetration of the east Australian current. Geophys Res Lett 34:L13613

Ritz DA, Hosie GW (1982) Production of the euphausiid Nyctiphanes australis in Storm Bay, south-eastern Tasmania. Mar Biol 68:103-108

Ropert-Coudert Y, Kato A, Chiaradia A (2009) Impact of small-scale environmental perturbations on local marine food resources: a case study of a predator, the little penguin. Proc R Soc B 276:4105-4109

Saraux C, Chiaradia A, Salton M, Dann P, Viblanc VA (2016) Negative effects of wind speed on individual foraging performance and breeding success in little penguins. Ecol Monogr 86:61-77

Stevenson C, Woehler E (2007) Population decreases in little penguins Eudyptula minor in southeastern Tasmania, Australia, over the past 45 years. Mar Orthinol 35: $61-66$

Sutton GJ, Hoskins AJ, Arnould JPY (2015) Benefits of group foraging depend on prey type in a small marine predator, the little penguin. PLOS ONE 10:e0144297

* Tosh CA, de Bruyn PJN, Steyn J, Bornemann H and others (2015) The importance of seasonal sea surface height anomalies for foraging juvenile southern elephant seals. Mar Biol 162:2131-2140

*Trathan PN, Bishop C, Maclean G, Brown P, Fleming A, Collins MA (2008) Linear tracks and restricted temperature ranges characterise penguin foraging pathways. Mar Ecol Prog Ser 370:285-294

*van Eeden R, Reid T, Ryan PG, Pichegru L (2016) Fine-scale foraging cues for African penguins in a highly variable marine environment. Mar Ecol Prog Ser 543:257-271

Vertigan CA (2010) The life-history of short-tailed shearwaters Puffinus tenuirostris in response to spatiotemporal environmental variation. $\mathrm{PhD}$ thesis, University of Tasmania, Hobart

Vertigan P, Woehler EJ (2014) Survey of little penguins in Kingborough, 2013/14. BirdLife Tasmania Report, Hobart

Ware C, Trites AW, Rosen DAS, Potvin J (2016) Averaged propulsive body acceleration (APBA) can be calculated from biologging tags that incorporate gyroscopes and accelerometers to estimate swimming speed, hydrodynamic drag and energy expenditure for Steller sea lions. PLOS ONE 11:e0157326

WWeavers BW (1992) Seasonal foraging ranges and travels at sea of little penguins Eudpytula minor, determined by radiotracking. Emu 91:302-317

*Weimerskirch H (2007) Are seabirds foraging for unpredictable resources? Deep Sea Res II 54:211-223

*Weimerskirch H, Zimmermann L, Prince PA (2001) Influence of environmental variability on breeding effort in a long-lived seabird, the yellow-nosed albatross. Behav Ecol 12:22-30

*Weimerskirch H, Gault A, Cherel Y (2005) Prey distribution and patchiness: factors in foraging success and efficiency of wandering albatrosses. Ecology 86:2611-2622

Wiebkin AS (2012) Feeding and breeding ecology of little penguins Eudyptula minor in the eastern Great Australian Bight. PhD thesis, University of Adelaide

* Yamamoto T, Kokubun N, Kikuchi DM, Sato N and others (2016) Differential responses of seabirds to environmental variability over 2 years in the continental shelf and oceanic habitats of southeastern Bering Sea. Biogeosciences 13:2405-2414

*Yasuda I, Sugisaki H, Watanabe Y, Minobe S, Oozeki Y (1999) Interdecadal variations in Japanese sardine and ocean/climate. Fish Oceanogr 8:18-24

Zhang J, O'Reilly KM, Perry GLW, Taylor GA, Dennis TE (2015) Extending the functionality of behavioural change-point analysis with $k$-means clustering: a case study with the little penguin Eudyptula minor. PLOS ONE 10:e0122811 